See Article page 82 .

\section{Commentary: On the road toward routine use of 3-dimensional techniques in complex congenital surgery}

\author{
Giovanni Biglino, $\mathrm{PhD},{ }^{\mathrm{a}, \mathrm{b}, \mathrm{c}}$ and \\ Massimo Caputo, MD, FRCS ${ }^{\mathrm{a}, \mathrm{b}}$
}

The goal of a successful repair in patients with tetralogy of Fallot, pulmonary atresia, and multiple aortopulmonary collateral arteries (MAPCAs) is to provide flow to the greatest number of lung segments. ${ }^{1}$ It is therefore fundamental for the surgeon to understand the relationship of the collateral vessels to other mediastinal structures, such as the trachea and esophagus, to plan the best surgical approach. Three-dimensional (3D) printing and visualization techniques are emerging as potentially valuable tools to inform the management of patients with MAPCAs, allowing reconstruction of 3D anatomic relationships from imaging data.

From an early small case series including 6 patients with pulmonary atresia with ventricular septal defect and MAPCAs reporting the surgeons' liking of the increased visualization of the vascular anatomy, ${ }^{2}$ isolated cases have highlighted the usefulness of 3D-printed models in similar scenarios, including:

- children with pulmonary atresia with ventricular septal defects and MAPCAs assessed for repair with right ventricle-to-pulmonary artery conduit ${ }^{3}$ or central shunt ${ }^{4}$ and unifocalization;

- a patient with DiGeorge syndrome, tetralogy of Fallot, pulmonary atresia. and MAPCAs ${ }^{5}$; and

- an adult patient with complex tetralogy of Fallot, pulmonary atresia, and MAPCAs undergoing redo surgery to

From the ${ }^{\mathrm{a} B}$ Bristol Medical School, University of Bristol, Bristol; ${ }^{\mathrm{b}}$ Bristol Heart Institute, University Hospitals Bristol, Bristol; and ${ }^{c}$ National Heart and Lung Institute, Imperial College London, London, United Kingdom.

Disclosures: Authors have nothing to disclose with regard to commercial support.

Received for publication Dec 13, 2019; revisions received Dec 13, 2019; accepted for publication Jan 3, 2020; available ahead of print Feb 3, 2020.

Address for reprints: Massimo Caputo, MD, FRCS, Bristol Heart Institute, Level 7 Bristol Royal Infirmary, BS2 8HW Bristol, United Kingdom (E-mail: m.caputo@bristol.ac.uk).

JTCVS Techniques 2020;1:88-9

2666-2507

Copyright $(\odot 2020$ The Author(s). Published by Elsevier Inc. on behalf of The American Association for Thoracic Surgery. This is an open access article under the CC BY-NC-ND license (http://creativecommons.org/licenses/by-nc-nd/4.0/).

https://doi.org/10.1016/j.xjtc.2020.01.015

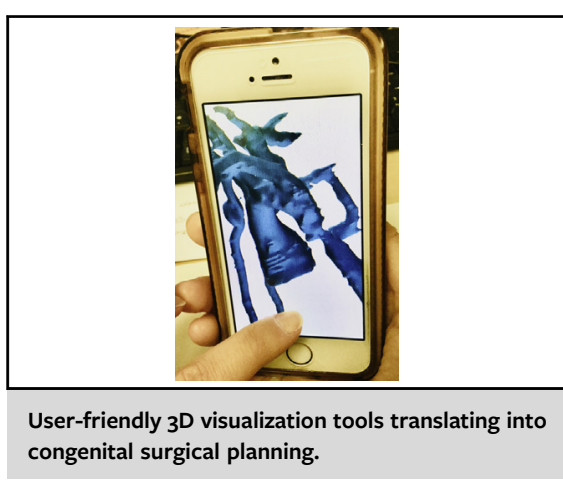

\section{CENTRAL MESSAGE \\ Three-dimensional (3D) technol- \\ ogies can aid in planning \\ congenital surgeries and are \\ increasingly being translated into \\ clinical practice, including the use \\ of physical 3D-printed models \\ but also agile visualization tools \\ such as 3D .pdf files.}

address increasing load on the right ventricle because of undersized conduits. ${ }^{6}$

The study by Ghosh and colleagues ${ }^{7}$ presents 3 cases of tetralogy of Fallot undergoing unifocalization for 4 to 5 MAPCAs for which, on top of the 3D-printed physical model, a 3D .pdf file was also provided to the surgeon as an additional visual aid, based on the information reconstructed from the computed tomography angiograms. The 3D .pdf file is a simple interactive tool allowing for rotating the $3 \mathrm{D}$ volume, zooming in/out, and removing anatomical structures. The authors note, in line with previous evaluation of $3 \mathrm{D}$ models in various congenital scenarios, that this tool substantially contributed to spatial orientation, particularly appreciating the position of the collaterals with respect to the pulmonary arteries. Perhaps even more interestingly, the authors mention that the models were "quickly adopted by the cardiothoracic surgical group," becoming "part of routine pre-surgical planning for this patient population."

Large, multicentric trials are still rare, ${ }^{8}$ yet the enthusiasm for 3D technologies remains high. This applies to physical models and 3D .pdf files but also to more immersive modalities, such as 3D virtual reality models for visualizing intra- and extracardiac structures. ${ }^{9}$ Although hard clinical outcomes and the potential impact of the use of 
3D technologies on variables such as reduced bypass time or decreased radiation dose during fluoroscopy are indisputably needed, it is interesting to consider these tools from a design angle, in light of improved user experience, where the "users" encompass surgeons and cardiologists, but also nurses, anesthetists, patients, and families.

3D visualization tools, as those presented by Ghosh and colleagues, can elucidate a structural issue and allow to remove structures to enhance such insight, where-in the words of German artist Hans Hofmann (1880-1966) "the ability to simplify means to eliminate the unnecessary so that the necessary may speak."

\section{References}

1. Nelson JS, Bove EL, Hirsch-Romano JC. Tetralogy of Fallot. In: Da Cruz E, Ivy D, Jaggers J, eds. Pediatric and Congenital Cardiology, Cardiac Surgery and Intensive Care. London: Springer; 2014.
2. Ngan EM, Rebeyka IM, Ross DB, Hirji M, Wolfaardt JF, Seelaus R, et al. The rapid prototyping of anatomic models in pulmonary atresia. $J$ Thorac Cardiovasc Surg. 2006;132:264-9.

3. Matsumoto JS, Morris JM, Foley TA, Williamson EE, Leng S, McGee KP, et al. Three-dimensional physical modeling: applications and experience at Mayo Clinic. Radiographics. 2015;35:1989-2006.

4. Ryan JR, Moe TG, Richardson R, Frakes DH, Nigro JJ, Pophal S. A novel approach to neonatal management of tetralogy of Fallot, with pulmonary atresia, and multiple aortopulmonary collaterals. JACC Cardiovasc Imaging. 2015;8:103-4.

5. Anwar S, Singh GK, Miller J, Sharma M, Manning P, Billadello JJ, et al $3 \mathrm{D}$ printing is a transformative technology in congenital heart disease. JACC Basic Transl Sci. 2018;3:294-312.

6. Deferm S, Meyns B, Vlasselaers D, Budts W. 3D-printing in congenital cardiology: from flatland to spaceland. J Clin Imaging Sci. 2016;6:8.

7. Ghosh RM, Silvestro E, O'Byrne ML, Whitehead KK. A road-map for collaterals: use of 3-dimensional techniques in tetralogy of Fallot pulmonary atresia with major aortopulmonary collateral arteries. J Thorac Cardiovasc Surg Tech. 2020;1:82-5.

8. Witowski J, Sitkowski M, Zuzak T, Coles-Black J, Chuen J, Major P, et al. From ideas to long-term studies: 3D printing clinical trials review. Int J Comput Assist Radiol Surg. 2018;13:1473-8.

9. Ong CS, Krishnan A, Huang CY, Spevak P, Vricella L, Hibino N, et al. Role of virtual reality in congenital heart disease. Congenit Heart Dis. 2018;13:357-61. 